\title{
ИММУННЫЕ И МЕТАБОЛИЧЕСКИЕ НАРУШЕНИЯ НА СИСТЕМНОМ И ЛОКАЛЬНОМ УРОВНЕ ПРИ БЕСПЛОДИИ ТРУБНО-ПЕРИТОНЕАЛЬНОГО ГЕНЕЗА
}

\author{
( Конопля А.А., По Омашарифа Бинти Жамал, Иванова О.Ю., Елагина К.А. \\ Курский государственный медицинский университет (КГМУ) \\ Россия, 305041, Курская область, г. Курск, ул. К. Маркса, д. 3
}

Цель: становление иммунных и метаболических нарушений на системном и местном уровне у женщин при трубно-перитонеальном бесплодии на фоне хронического инфекционно-воспалительного процесса репродуктивной системы в стадии клинической ремиссии до и после базовой фармакотерапии.

Материалы и методы. Под наблюдением находились 96 женщин с полностью подтвержденным диагнозом вторичное бесплодие трубно-перитонеального генеза на фоне хронического инфекционно-воспалительного процесса бактериально-вирусной этиологии в стадии ремиссии. В периферической крови и цервикальновлагалищном смыве выявляли параметры иммунного статуса, интенсивность процессов перекисного окисления липидов и состояние антиоксидантной системы.

Результаты. В течение суток после лечебно-диагностической лапароскопии на системном и локальном уровне установлено наличие иммунного воспаления, эндотелиальной дисфункции, «окислительного стресса», активация процессов перекисного окисления липидов, о чем свидетельствовало изменение 97,8\% лабораторных иммунометаболических показателей от числа изученных. После проведенной базовой фармакотерапии этот процент снизился до 90,9\%, при этом нормализовалось 9,1\%, корригировалось 75,0\% от нарушенных лабораторных параметров, 15,9\% остались без изменения.

Заключение. Результаты данного исследования говорят о том, что проводимая базовая фармакотерапия у данной категории больных не корригирует нарушения параметров иммунного и метаболического статуса, что, в свою очередь, обосновывает необходимость применения в раннем послеоперационном периоде у этой категории больных дополнительных способов фармакологической реабилитации.

Ключевые слова: бесплодие трубно-перитонеального генеза; иммунометаболические нарушения.

Конопля Алексей Александрович - д-р мед. наук, доцент, профессор кафедры акушерства и гинекологии ФПО, КГМУ, г. Курск. ORCID iD: 0000-0001-5040-7499. E-mail: kanabis03101980@yandex.ru (автор, ответственный за переписку)

По Омашарифа Бинти Жамал - ассистент кафедры акушерства и гинекологии ФПО, КГМУ, г. Курск. ORCID iD: 0000-00024128-7576. E-mail: drmno131@yahoo.com

Иванова Оксана Юрьевна - д-р мед. наук, доцент, профессор кафедры акушерства и гинекологии, КГмУ, г. Курск. ORCID iD: 0000-0003-2350-1740. E-mail: ivanovao1@mail.ru

Елагина Карина Александровна - клинический ординатор кафедры акушерства и гинекологии, КГМУ, г. Курск. ORCID iD: 0000-0002-8186-0074. E-mail: karina.boeva.95@mail.ru

По данным литературы, в настоящее время каждая пятая супружеская пара встречается с проблемой бесплодия. Доля женского фактора в структуре данного заболевания составляет $45 \%$, мужского - $40 \%$, и $15 \%$ приходится на их сочетание. Анатомо-функциональные нарушения маточных труб в сочетании со спаечным процессом малого таза являются одной из наиболее частых причин женской инфертильности (50$60 \%$ ), что позволило выделить понятие трубноперитонеального бесплодия. Предикторами развития данного состояния являются воспалительные заболевания органов малого таза (BЗОМТ), которые являются причиной амбулаторных обращений более $60 \%$ пациенток амбулаторного звена и служат причиной каждой третьей госпитализации женщины в гинекологический стационар. Помимо этого, специалисты все чаще сталкиваются с затруднениями в своевременной диагностике ВЗОМТ в связи с частым отсутствием симптомов и/или атипичной клинической картиной, что ведет к не- своевременному и неадекватному выбору лечебной тактики $[1,2,4,19]$.

Запоздалая или некорректная терапия ВЗОМТ приводит к хроническому рецидивирующему течению воспалительного процесса, развитию спаечного процесса в малом тазе, что ухудшает репродуктивный прогноз пациентки $[7,12,20]$. Помимо этого, тенденция к хронизации способствует вовлечению в патологический процесс иммунной, эндокринной систем и появлению как локальной, так и общесоматической симптоматики $[11,18,21]$.

Золотым стандартом диагностики бесплодия трубно-перитонеального генеза является диагностическая лапароскопия, однако сам факт оперативного вмешательства, наличие анестезиологического пособия, антибиотикопрофилактика неблагоприятно влияют на иммунную систему, что приводит к неадекватной реабилитации пациенток $[11,13,22]$.

Цель исследования: установление иммунных и метаболических нарушений на систем- 
ном и местном уровне у пациенток при бесплодии трубно-перитонеального генеза на фоне хронического инфекционно-воспалительного процесса репродуктивной сферы в стадии клинической ремиссии до и после базовой фармакотерапии.

\section{МАТЕРИАЛЫ И МЕТОДЫ ИССЛЕДОВАНИЯ}

За период 2010-2018 гг. под постоянным наблюдением в гинекологическом отделении ОБУЗ «Курский перинатальный центр» и ГКБ № 4 г. Курска находились 96 пациенток, направленных в стационар для проведения диагностической лапароскопии по поводу бесплодия трубно-перитонеального генеза. С целью верификации трубно-перитонеального генеза бесплодия и исключения его других форм всем пациенткам проводилось стандартное клиниколабораторное обследование, включающее сбор семейного и акушерско-гинекологического анамнеза, инфекционный скрининг (микроскопическое исследование мазков из влагалища, цервикального канала и уретры; ПЦРдиагностика хламидиоза и герпесвирусной инфекции; обследование на сифилис (RW), гепатит B, C (HBsAg, анти HCV-антител); определение антител класса IgG, IgM к инфектам TORCH-комплекса), оценку овуляторной функции (тест на овуляцию «Клиоплан»), УЗИ органов малого таза.

В критерии включения были определены следующие параметры:

- возрастная группа пациенток от 18 до 40 лет;

- полностью подтвержденный диагноз вторичное бесплодие трубно-перитонеального генеза на фоне хронического инфекционновоспалительного процесса бактериальновирусной этиологии в стадии ремиссии;

- наличие отягощенного акушерскогинекологического анамнеза (хронические воспалительные заболевания органов малого таза, бесплодие в анамнезе, самопроизвольные выкидыши, невынашивание беременности, аборты);

- длительность заболевания до 10 лет;

- отсутствие тяжелой экстрагенитальной патологии;

- результаты отрицательных обследований на инфекции, которые передаются половым путем (ИППП);

- первое оперативное лечение;

- специализированное письменное согласие на добровольное участие в исследованиях.
Критериями исключения из исследования стали:

- пациентки с мужским, маточным, эндокринным и цервикальным генезом бесплодия;

- пациентки, имеющие в анамнезе оперативное вмешательство;

- пациентки с подтвержденной специфической ИППП;

- наличие сопутствующей соматической патологии в стадии обострения или неполной ремиссии;

- лица с отягощенным аллергоанамнезом;

- отказ в участии в исследовании.

Рандомизация строилась по возрасту, длительности анамнеза болезни, способу проводимого лечения, сопутствующей патологии в стадии ремиссии. В группу контроля вошли здоровые женщины этого же возраста.

Лабораторные методы исследования крови проводились по общепринятым методикам. При оценке гемограмм брались за основу физиологические нормы, соответствующие Международной системе единиц (СИ) в клинических исследованиях.

Лабораторное обследование осуществляли через 24 часа после операции и на 30-е сутки после базовой фармакотерапии (БФТ), включающей антибактериальные, противогрибковые средства, витаминотерапию.

Интенсивность процессов перекисного окисления липидов (ПОЛ) оценивали по содержанию в плазме крови и вагинальноцервикальном смыве малонового диальдегида и ацилгидроперекисей (МДА, АГП) с помощью набора «ТБК-Агат», состояние антиоксидантной системы - по общей антиокислительной активности (ОАА) и активности супероксиддисмутазы (СОД). С применением коммерческих наборов для твердофазного иммуноферментного анализа (ИФА) определяли уровень стабильных метаболитов оксида азота $\left(\mathrm{CM}_{\mathrm{NO}}\right)$, неоптерина, C-реактивного белка (CRB).

В плазме крови и вагинально-цервикальном

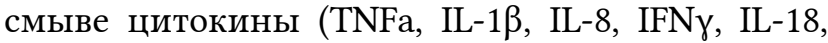
G-CSF, IL-4, IL-10), иммуноглобулины классов M, G, A (IgM, IgG, IgA), секреторного иммуноглобулина A (sIgA) выявляли методом ИФА с использованием наборов $3 \mathrm{AO}$ «Вектор Бест» (Россия), а компоненты системы комплемента $\left(\mathrm{C}_{3}, \mathrm{C}_{4}, \mathrm{C}_{5}\right.$, $\left.\mathrm{C}_{5 \mathrm{a}}\right)$ - диагностическим набором ООО «Цитокин» (Россия). Активность С1-ингибитора определяли хромогенным методом по способности ингибировать $\mathrm{C}_{1}$-эстеразу. Регистрация осуществлялась при помощи микропланшетного фотометра «Sunrise», Тесаn (Австрия).

Фагоцитарную активность полиморфноядерных лейкоцитов крови после их выделения 
из крови на градиенте плотности фиколлурографин $(\mathrm{d}=1,077)$ оценивали, определяя общепринятыми методами фагоцитарный индекс $(Ф И)$, фагоцитарное число (ФЧ) и индекс активности фагоцитоза (ИАФ). Активность кислородзависимых систем нейтрофилов оценивали на спектрофотометре PD 303 SApel (Япония) по реакции восстановления нитросинего тетразолия (НСТ-тест), спонтанного и стимулированного зимозаном (НСТ-сп., НСТ-ст.) и функциональному резерву нейтрофилов (ФРН) [8].

Все клинико-инструментальные исследования и фармакологическая коррекция происходили только с информированного согласия пациенток на применение материалов лечебнодиагностических мероприятий, связанных с данным заболеванием, исключительно для научно-исследовательских целей.

Статистическую и математическую обработку результатов исследования проводили по критериям вариационно-статистического анализа с вычислением средних величин (М), ошибки средней арифметической (m) с применением пакета компьютерных программ Microsoft Excel, 2010. Существенность различий оценивали по U-критерию. Статистически значимыми считали только те различия, которые соответствовали $\mathrm{p}<0,05$.

\section{РЕЗУЛЬТАТЫ ИССЛЕДОВАНИЯ И ИХ ОБСУЖДЕНИЕ}

Общая характеристика больных с ФП. Через 24 часа после лечебно-диагностической лапароскопии у пациенток с вторичным бесплодием трубно-перитонеального генеза на фоне хронического инфекционно-воспалительного процесса бактериально-вирусной этиологии в стадии ремиссии на системном уровне (плазма крови) повышен уровень провоспалительных (TNFa, IL-1 $\beta$, IL-8, IL-18), противовоспалительных (IL-4, IL-10), IFNy, G-CSF цитокинов. Кроме этого, выявлен дисбаланс в содержании иммуноглобулинов: повышение класса M (IgM) и снижение $\operatorname{IgG}$ и $\operatorname{Ig} A$.

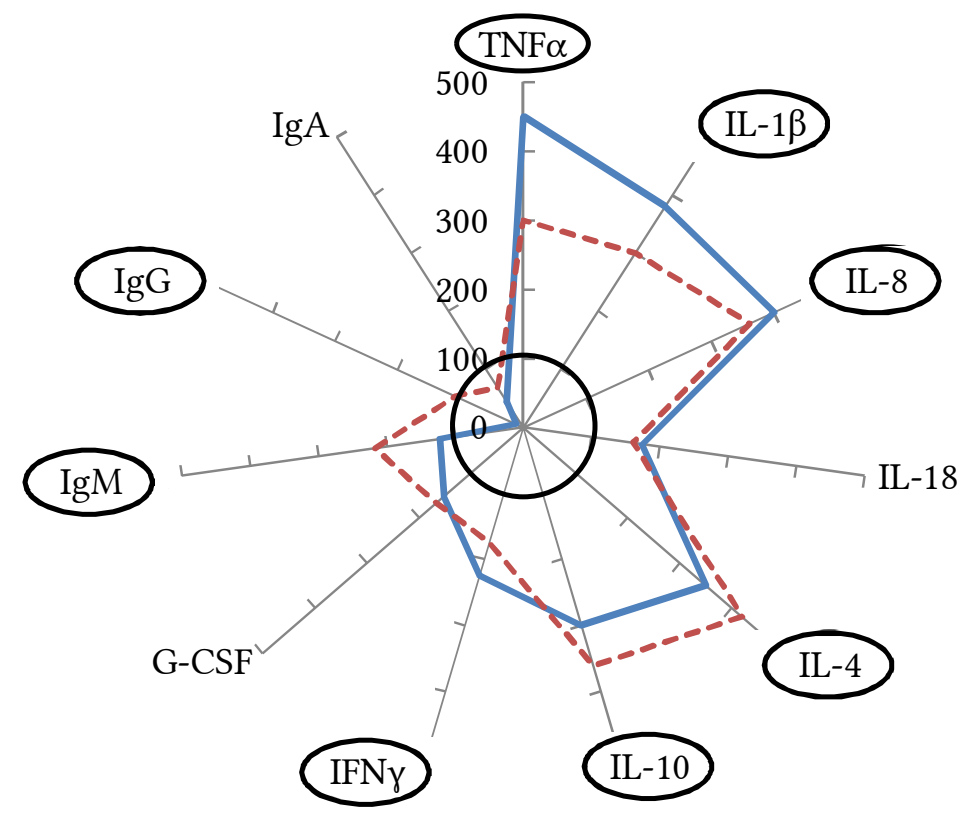

Рис. 1. Цитокины и иммуноглобулины в плазме крови у пациенток с бесплодием трубноперитонеального генеза до и после базового лечения.

Примечание: на этом и последующих рисунках (1-4): радиус окружности - показатели у здоровых женщин (условная норма) (1 группа); _- показатели у пациенток до лечения (2 группа); - - - показатели у пациенток после базового лечения (3 группа); все изученные показатели достоверно отличаются от уровня нормы $(\mathrm{p}<0,05) ; \bigcirc$ - $<<0,05$ между показателями 2 и 3 группами; TNF $\alpha-$ фактор некроза опухоли альфа; IL-1 $\beta$ - интерлейкин-1 бета; IL-8, IL-18, IL-4, IL-10 - интерлейкины 8, 18, 4, 10; IFNy - интерферон-гамма; G-CSF - колониестимулирующий фактор нейтрофилов; IgM, IgG, $\operatorname{IgA~-~иммуноглобулины~классов~M,~G,~A.~}$

Fig. 1. Plasma cytokines and immunoglobulins in patients with tubal peritoneal genesis infertility before and after basic treatment.

Note: in this and the further figures (1-4): the radius of the circle - indicators in healthy women (notional rate) (1 group); - indicators in patients before treatment (group 2); -- indicators in patients after basic treatment (group 3); all studied parameters significantly differ from the norm level $(\mathrm{p}<0.05) ; \bigcirc \mathrm{p}<0.05$ between indicators 2 and 3 groups; TNF $\alpha$ - tumor necrosis factor alpha; IL-1 $\beta$ - interleukin-1 betta; IL-8, IL-18, IL-4, IL-10 - interleukins 8, 18, 4, 10; IFN - interferon-gamma; G-CSF - neutrophil colony stimulating factor; IgM, $\operatorname{IgG}, \operatorname{Ig} \mathrm{A}-$ immunoglobulins of classes $\mathrm{M}, \mathrm{G}, \mathrm{A}$. 


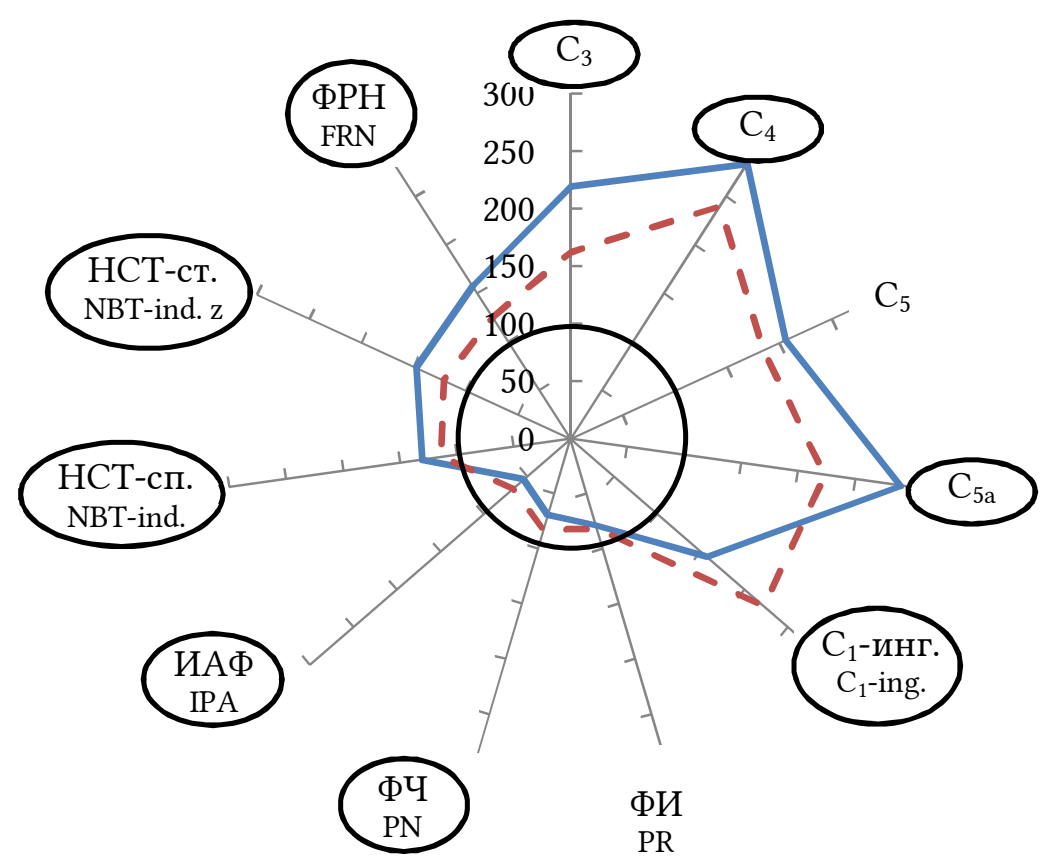

Рис. 2. Система комплемента и функционально-метаболическая активность нейтрофилов циркулирующей крови у пациенток с бесплодием трубно-перитонеального генеза до и после базового лечения.

Примечания: $\mathrm{C}_{3}, \mathrm{C}_{4}, \mathrm{C}_{5}, \mathrm{C}_{5 \mathrm{a}}$ - компоненты системы комплемента; $\mathrm{C}_{1}$-инг. - $\mathrm{C}_{1}$-ингибитор системы комплемента; ФИ - фагоцитарный индекс; ФЧ - фагоцитарное число; ИАФ - индекс активности фагоцитоза; НСТ-сп. и НСТ-ст. - реакции восстановления нитросинего тетразолия спонтанного и стимулированного зимозаном; $Ф$ РН - функциональный резерв нейтрофилов.

Fig. 2. Compliment system and functional-metabolic activity of circulating blood neutrophils in patients with tubal peritoneal genesis infertility before and after basic treatment.

Notes: $\mathrm{C}_{3}, \mathrm{C}_{4}, \mathrm{C}_{5}, \mathrm{C}_{5 \mathrm{a}}$ - components of the complement system; $\mathrm{C}_{1}$-ing. $-\mathrm{C}_{1}$ - inhibitor of the complement system; $\mathrm{PR}-\mathrm{phagocytic}$ index; PN - phagocytic number; IPA - phagocytosis activity index; NBT-ind. -the restore reaction of nitro blue tetrazolium; NBT-ind. $\mathrm{z}$ - spontaneous and stimulated by zymosan; FRN - functional reserve of neutrophils.

Применение БФТ позволило у данной категории пациенток на 30 сутки после нее нормализовать уровень $\mathrm{IgG}$, повысить в большей степени содержание IgM и противовоспалительных цитокинов и приблизить к показателям доноров, но не до их значений, концентрацию противовоспалительных цитокинов (за исключением IL-18) и G-CSF (рис. 1).

В плазме крови пациенток с трубноперитонеальным бесплодием также повышен уровень компонентов системы комплемента $\left(\mathrm{C}_{3}\right.$, $\mathrm{C}_{4}, \mathrm{C}_{5}, \mathrm{C}_{5 \mathrm{a}}$ ) и компенсаторно ингибитора системы комплемента (С1-инг.). Изучение функционально-метаболической активности нейтрофилов циркулирующей крови показало снижение их фагоцитарной активности (снижение ФИ,

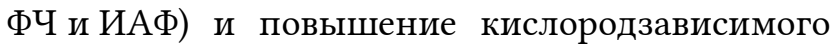
метаболизма (повышение НСТ-сп., НСТ-ст. и ФРН) (рис. 2).

Использование БФТ позволило в большей степени повысить содержание $\mathrm{C}_{1}$-инг., приблизить к параметрам нормы, но не до их значений, ФЧ, ИАФ, НСТ-ст., ФРН, концентрацию $\mathrm{C}_{3}$, $\mathrm{C}_{4}, \mathrm{C}_{5 \mathrm{a}}$. При этом содержание $\mathrm{C}_{5}$-компонета комплемента и ФИ не изменились, а НСТ-сп. был нормализован (рис. 2).
Кроме этого, на системном уровне определялось повышение содержания продуктов ПОЛ (МДА и АГП), маркеров воспаления (неоптерин и $\mathrm{CRB}$ ), стабильных метаболитов оксида азота и снижение факторов антиоксидантной защиты (ОАА, активность СОД и концентрация ЦП) при повышении активности каталазы. Применение БФТ позволило корригировать (приблизить к значениям доноров, но не до их уровня) концентрацию продуктов ПОЛ, ЦП, CRB, $\mathrm{CM}_{\mathrm{NO}}$, активность СОД, ОАА, оставив без изменения уровень неоптерина и повысив еще в большей степени активность каталазы (рис. 3).

На местном уровне (вагинально-цервикальный смыв) у пациенток с трубно-перитонеальным бесплодием из параметров иммунного статуса оказался повышен уровень провоспалительных цитокинов (TNFa и IL-8), секреторного иммуноглобулина A (sIgA), в отличие от системного уровня, снижена концентрация противовоспалительных цитокинов (IL-4 и IL-10). Кроме того, выявлена активация системы комплемента (повышено содержание $\mathrm{C}_{3}$ и $\mathrm{C}_{4}$ компонентов комплемента со снижением концентрации $\mathrm{C}_{1}$-ингибитора). После БФТ к уровню параметров контроля приблизилось содержание 
изученных про- и противовоспалительных цитокинов, $\mathrm{C}_{3}$-компонента комплемента, sIgA, но осталась на уровне начала БФТ концентрация $\mathrm{C}_{4}$-компонента системы комплемента и $\mathrm{C}_{1^{-}}$ ингибитора (рис. 4).

У данной категории пациенток на локальном уровне из исследованных метаболических параметров установлено повышение содержания МДА, АГП и СМ $\mathrm{CM}_{\mathrm{NO}}$, снижение маркеров антиоксидантной защиты (ОАА и активности каталазы), без изменений остался уровень неоптерина. После БФТ нормализовалась ОАА и активность каталазы, корригировались показатели ПОЛ и осталось без изменения содержание стабильных метаболитов оксида азота и неоптерина (рис. 4).

Сравнивая количество суммарных различий показателей с уровнем нормы при трубноперитонеальном бесплодии выявлено, что до лечения, таких показателей было 97,8\% от числа изученных. После проведенной БФТ этот процент снизился до 90,9\%, при этом нормализовалось всего 9,1\%, корригировалось 75,0\% изученных лабораторных параметров, но 15,9\% осталось на уровне БФТ, что свидетельствует о недостаточной фармакореабилитации (табл. 1).
Таким образом, у пациенток с бесплодием имеет место изменение большинства изученных показателей иммунного статуса на системном и локальном уровне, развивается эндотелиальная дисфункция, «окислительный стресс», что приводит к активации процессов ПОЛ.

Выявленные изменения на системном и местном уровне цитокинового статуса, активация системы комплемента, повышение кислородзависимой активности нейтрофилов периферической крови (возрастания образования активных форм кислорода в результате кислородного взрыва) свидетельствует о наличии иммунного воспаления.

Установленное нами у пациенток с бесплодием трубно-перитонеального генеза на фоне хронического инфекционно-воспалительного процесса бактериально-вирусной этиологии в стадии ремиссии увеличение в системной циркуляции содержания хемокинов и провоспалительных интерлейкино (IL-18, IL- $1 \beta, \mathrm{TNF} \alpha$, IL-8) с уменьшением концентрации противовоспалительного цитокина IL-4 отражает реакцию резидентных и рекрутированных клеток врожденного иммунитета на молекулярные паттерны, тесно связанные с повреждением [3, $23,24,25]$.

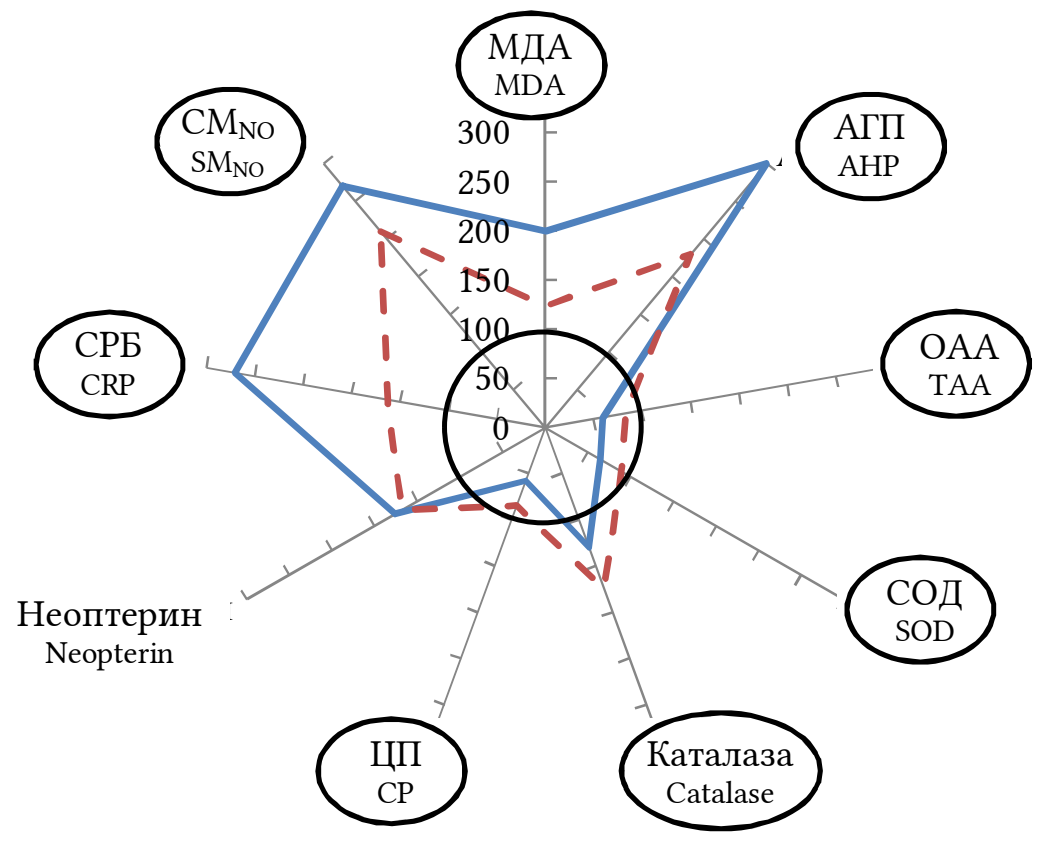

Рис. 3. Метаболические нарушения на системном уровне (плазма циркулирующей крови) у пациенток с бесплодием трубно-перитонеального генеза до и после базового лечения.

Примечания: МДА - малоновый диальдегид; АГП - ацилгидроперекиси; ОАА - общая антиокислительная активность; СОД - супероксиддисмутаза; ЦП - церулоплазмин; СРБ - С-реактивный белок; $\mathrm{CM}_{\mathrm{NO}}$ - стабильные метаболиты оксида азота.

Fig. 3. Metabolic disorders at the system level (circulating blood plasma) in patients with tubal peritoneal genesis infertility before and after basic treatment.

Notes: MDA - malondialdehyde; AHP - acylhydroperoxides; TAA - total antioxidant activity; SOD - superoxide dismutase; $\mathrm{CP}$ - ceruloplasmin; $\mathrm{CRP}$ - C-reactive protein; $\mathrm{SM}_{\mathrm{ON}}$ - stable metabolites of nitric oxide. 


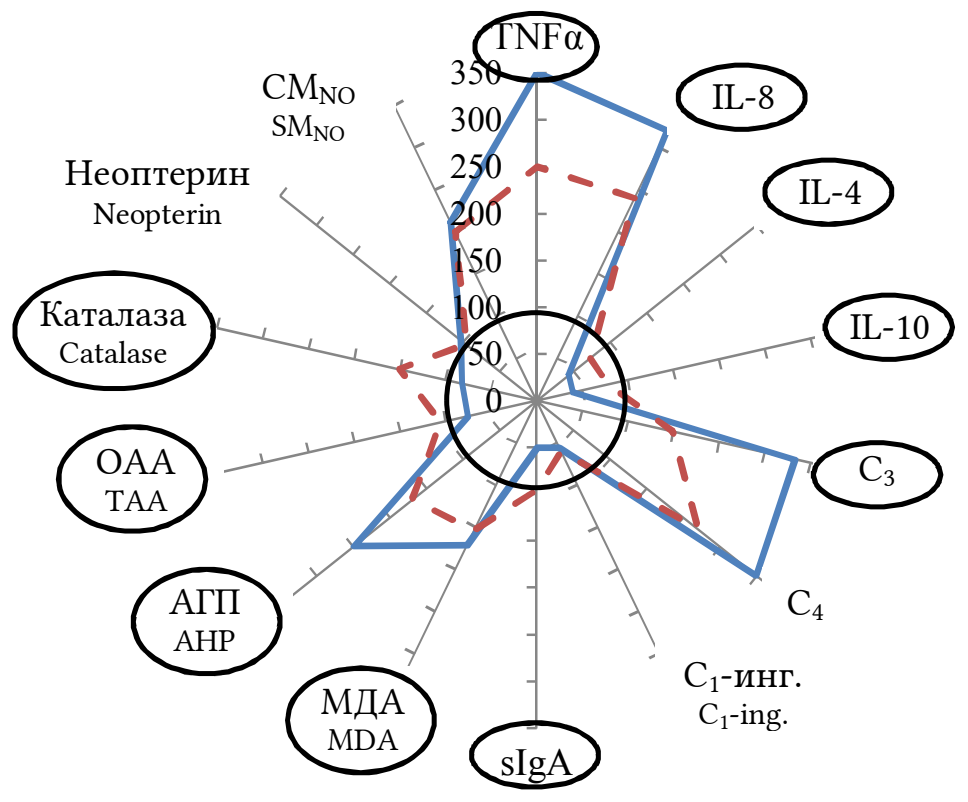

Рис. 4. Иммунометаболические нарушения на местном уровне (вагинально-цервикальный смыв) у пациенток с бесплодием трубно-перитонеального генеза до и после базового лечения.

Примечания: TNF $\alpha$ - фактор некроза опухоли альфа; IL-8, IL-4, IL-10 - интерлейкины 8, 4, 10; $\mathrm{C}_{3}, \mathrm{C}_{4}$ - компоненты системы комплемента; $\mathrm{C}_{1}$-инг. - $\mathrm{C}_{1}$-ингибитор системы комплемента; sIgA - секреторный иммуноглобулин А; МДА - малоновый диальдегид; АГП - ацилгидроперекиси; ОАА - общая антиокислительная активность; $\mathrm{CM}_{\mathrm{ON}}$ - стабильные метаболиты оксида азота.

Fig. 4. Immunometabolic disorders at the local level (vaginal-cervical lavage) in patients with tubal peritoneal genesis infertility before and after basic treatment.

Notes: TNF $\alpha$ - tumor necrosis factor alpha; IL-8, IL-4, IL-10 - interleukins 8, 4, 10; $\mathrm{C}_{3}, \mathrm{C}_{4}$ - components of the complement system; $\mathrm{C}_{1}$-ing. $-\mathrm{C}_{1}$-inhibitor of the complement system; sIgA - secretory immunoglobulin A; MDA - malondialdehyde; AHP - acylhydroperoxides; TAA - total antioxidant activity; $\mathrm{SM}_{\mathrm{ON}}$ - stable metabolites of nitric oxide.

Таблица 1 Table 1

Эффективность базовой фармакотерапии в послеоперационном периоде при трубно-перитонеальном бесплодии

The effectiveness of basic pharmacotherapy in patients with tubal-peritoneal infertility

\begin{tabular}{|l|c|}
\hline \multicolumn{1}{|c|}{\begin{tabular}{c}
\multicolumn{1}{|c|}{ Показатели (\% от общего количества показателей) } \\
Indicators (\% of the total number of indicators)
\end{tabular}} & $\begin{array}{c}\text { Бесплодие } \\
\text { Infertility }\end{array}$ \\
\hline $\begin{array}{l}\text { Отличные от уровня нормы до лечения } \\
\text { Different from the normal level before treatment }\end{array}$ & 97.8 \\
\hline $\begin{array}{l}\text { Hopмализованные } \\
\text { Normalized }\end{array}$ & 9.1 \\
\hline $\begin{array}{l}\text { Корригированные } \\
\text { Corrected }\end{array}$ & 75.0 \\
\hline $\begin{array}{l}\text { Не измененные } \\
\text { Not modified }\end{array}$ & 15.9 \\
\hline $\begin{array}{l}\text { Отличные от уровня нормы после базовой фармакотерапии } \\
\text { Non-normal after standard рharmacotherapу }\end{array}$ & 90.9 \\
\hline
\end{tabular}

Большая концентрация IFNy (который выступает реализатором клеточного иммунного ответа воспалительного типа), а также пролонгированное сохранение в крови повышенного соотношения IFN $\gamma / \mathrm{IL}-4$, не уменьшающегося после БФТ, свидетельствует об активации IFNy- продуцирующих NK-клеток, которые являются лимфоидными клетками врожденного иммунитета 1-го типа (ILC-1), обеспечивающие поляризацию дифференцировки Т-клеток в сторону T-хелперов 1-го типа (Th1), активирующих макрофаги, экспрессирующие ферменты, которые 
отвечают за формирование активных форм $\mathrm{O}_{2}$, активацию NO-синтазы с образованием NO. Существенное увеличение содержания колонистимулирующего фактора G-CSF, также не снижающееся после проведенного БФТ, может активировать зрелые нейтрофилы и поддерживать рост как отдельных колоний гранулоцитов и моноцитов/макрофагов, так и смешанных гранулоцитарно-моноцитарных колоний. Все это повышает синтез и секрецию колониестимулирующих факторов, провоспалительных цитокинов и хемокинов $[15,16,26]$.

Кроме этого, проведенное нами исследование показывает, что у пациенток данной категории имеется сочетание активации ПОЛ с развитием оксидантного стресса (повышение на системном и местном уровне концентрации продуктов ПОЛ (МДА, АГП), $\mathrm{CM}_{\mathrm{NO}}$ и $\mathrm{CRB}$; значительное снижением показателей антиоксидантной защиты (ОАА, ЦП, активности СОД, каталазы) $[6,14]$ с эндотелиальной дисфункцией (повышение вазодилатирующего $\left(\mathrm{CM}_{\mathrm{ON}}\right)$ фактора, повышенный уровень провоспалительных цитокинов (TNF $\alpha, \mathrm{IL}-1 \beta)$, неоптерина и CRB) $[5,9$, $17,10]$.

Полученные в результате исследования данные говорят о том, что проводимая БФТ у пациенток с трубно-перитонеальным бесплодием не оказывает соразмерного корригирующего влияния на нарушенные параметры метаболического и иммунного статуса, а это, в свою очередь, говорит о наличии воспалительного процесса и необходимости применения в раннем послеоперационном периоде у данной категории больных дополнительных способов фармакологической реабилитации.

\section{КОНФЛИКТ ИНТЕРЕСОВ}

Авторы декларируют отсутствие явных и потенциальных конфликтов интересов, связанных с публикацией настоящей статьи.

\section{ИСТОЧНИКИ ФИНАНСИРОВАНИЯ}

Авторы заявляют об отсутствии финансирования.

\section{СООТВЕТСТВИЕ ПРИНЦИПАМ ЭТИКИ}

Исследование одобрено Региональным этическим комитетом. Протокол заседания РЭК № 4 от 8 апреля 2019 года.

\section{ЛИTЕРАTУPA/REFERENCES}

1. Айламазян Э.К., Толибоева Г.Х., Траль Т.Г., Цыпуреева Н.Д., Юркова И.К., Кахиани М.И. Клинико-морфологические детерминанты бесплодия, ассоциированного с воспалительными заболеваниями органов малого таза. Журнал акушерства и женских болезней. 2015; 64(6):17-25 [Ayla- mazyan E.K., Toliboyeva G.Kh., Tral' T.G., Tsypureyeva N.D., Yurkova I.K., Kakhiani M.I. linical and morphological determinants of infertility associated with inflammatory diseases of the pelvic organs. Journal of obstetrics and women diseases. 2015; 64(6):17-25 (in Russ.)]

2. Антимирова Е.А., Летяева О.И., Дольникова О.А. Состояние локального иммунитета репродуктивной системы женщин с воспалительными заболеваниями, ассоциированными с бактериально-вирусной инфекцией. Российский иммунологический журнал. 2016; 10-19(3):214-216 [Antimirova E.A., Letyaeva O.I., Dolnikova O.A The state of local immunity of female reproductive system inflammatory diseases associated with bacterial-viral infection. Russian fournal of Immunology. 2016; 10-19(3):214-216. (in Russ.)]

3. Белан Э.Б., Пахуридзе Р.Ф., Смолова Н.В., Андреева M.В. Уровень IL-8 в сыворотке крови как маркер течения воспалительного процесса у больных с гинекологической патологией. Цитокины и воспаление. 2011; 10(3):55-60 [Belan E.B., Pakhuridze R.F., Smolova N.V., Andreeva M.V. IL-8 serum level as a marker of the inflammatory process in patients with gynecological pathologies. Tsitokiny $i$ vospaleniye. 2011; 10(3):55-60 (in Russ.)]

4. Буралкина Н.А., Каткова А.С., Арутюнова Е.Э., Жорова В.Е., Батырова 3.К., Власова Г.А. Воспалительные заболевания органов малого таза: патогенетические аспекты, диагностика, клиника, лечение (обзор литературы). Гинекология. 2018; 20(3):12-15 [Buralkina N.A., Katkova A.S., Arutyunova E.E., Zhorova V.E., Batyrova Z.K., Vlasova G.A. Inflammatory diseases of the pelvic organs: pathogenetic aspects, diagnosis, clinic, treatment (review). Gynecology. 2018; 20(3):12-15 (in Russ.)] DOI: 10.26442/2079-5696_2018.3.12-15

5. Гладких Р.А., Молочный В.П., Полеско И.В. Неоптерин как современный маркер воспаления. Детские инфекиии. 2016;15(2):19-23 [Gladkikh R.A., Molochniy V.P., Polesko I.V. Neopterin as a Modern Marker of Inflammation. Detskie infekcii. 2016; 15(2):19-23 (in Russ.)]

6. Горожанская Э.Г. Свободнорадикальное окисление и механизмы антиоксидантной защиты в нормальной клетке и при опухолевых заболеваниях. Клиническая лабораторная диагностика. 2010; 6:28-44 [Gorozhanskaya E.G. Free radical oxidation and the mechanisms of antioxidant defense in the normal cell and tumor diseases (a lecture). Klinicheskaya laboratornaya diagnostika. 2010; 6:2844 (in Russ.)]

7. Жеребятьева О.О., Сетко Н.П., Михайлова Е.А., Киргизова С.Б., Константинова О.Д., Кшнясева С.К., Махалова Г.О., Ляшенко И.Э. Иммунологические критерии прогнозирования вторичного бесплодия. Российский иммунологический журнал. 2015; 9-18(2-1):378-379 [Zherebyateva O.O., Setko N.P., Mikhailova E.A., Kirgizova S.B., Konstantinova O.D., Kshnyaseva S.K., Makhalova G.O., Lyashenko I.E. Immunological criteria for forecasting the secondary sterility. Russian fournal of Immunology. 2015; 9-18(2-1):378-379 (in Russ.)] 
8. Зинкин В.Ю., Годков В.Г. Способ оценки кислородзависимого метаболизма нейтрофильных гранулоцитов человека. Клиническая лабораторная диагностика. 2004; 2;27-31 [Zinkin B.Yu., Godkov B.G. Method for assessing oxygen-dependent metabolism of human neutrophil granulocytes. Klinicheskaya laboratornaya diagnostika. 2004; 2;27-31 (in Russ.)]

9. Зорина В.Н., Лихачева В.В., Зорина Р.М., Баженова Л.Г., Третьякова Т.В., Архипова С.В., Ренге Л.В., Зорин Н.А. Дисбаланс в системе «Цитокиновая сеть - регуляторно-транспортные белки» при различных видах бесплодия в программах экстракорпорального оплодотворения. Медицинская иммунология. 2018; 20(2):203-214 [Zorina V.N., Likhacheva V.V., Zorina R.M., Bazhenova L.G., Tretyakova T.V., Arkhipova S.V., Renge L.V., Zorin N.A. Imbalance in cytokine network/regulatory transport protein system in various types of infertility during in vitro fertilization programs. Meditsinskaya Immunologiya. 2018; 20(2):203-214 (in Russ.)] DOI: 10.15789/1563-0625-2018-2-203-214

10. Конопля А.А., Газазян М.Г., Караулов А.В. Применение иммуномодуляторов в комплексном лечении хронического сальпингоофорита. Акушерство и гинекология. 2010; 4:75-78 [Konoplya A.A., Gazazyan M.G., Karaulov A.V. Use of immunomodulators in the complex treatment of chronic salpingoophoritis. Akusherstvo i ginekologiya. 2010; 4:75-78 (in Russ.)]

11. Конопля А.А., Караулов А.В., Конопля А.И., Гаврилюк В.П. Взаимосвязь коррекции иммунных и оксидантных нарушений со структурнофункциональными свойствами эритроцитов при хронических сальпингоофоритах: монография. Курск: ГОУ ВПО КГМУ Росздрава, 2009. 180 с. [Konoplya A.A., Karaulov A.B., Konoplya A.I., Gavrilyuk V.P. Correlation of correction of immune and oxidant disorders with structural and functional properties of erythrocytes in chronic salpingoophorites: monograph. Kursk: KSMU, 2009. 180 p. (in Russ.)]

12. Мусаходжаева Д.А., Маликова Д.Б., Курбанов Д.Д., Музафарова С.А. Цитокиновый профиль цервикальной слизи у женщин с бесплодием воспалительного генеза. Аллергология и иммунология. 2014; 15(3):212-213 [Musakhodzhayeva D.A., Malikova D.B., Kurbanov D.D., Muzafarova S.A. Cytokine profile of cervical mucus in women with infertility of inflammatory genesis. Allergologiya $i$ immunologiya. 2014; 15(3):212-213 (in Russ.)]

13. Надей Е.В., Нечаева Г.И., Шупина М.И. Оптимизация комплексной терапии воспалительных заболеваний женских половых органов с позиции клинической иммунологии. Акушерство и гинекология. 2015; 10:97-102 [Nadey E.V., Nechayeva G.I., Supina M.I. Optimization of combination therapy for female genital inflammatory diseases in the context of clinical immunology. Akusherstvo $i$ ginekologiya. 2015; 10:97-102 (in Russ.)]

14. Ниаури Д.А., Чепур С.В., Попов Э.Н., Харитонов К.П., Кузнецова И.В. Участие свободнорадикальных процессов в возможных механизмах развития сочетанных гиперпластических про- цессов органов репродуктивной системы женщин. Журнал акушерства и женских болезней. 2005; 54(2):31-35 [Niauri D.A., Chepur S.V., Popov E.N., Charitonov K.P., Kuznetsova I.V. Free radical reactions in the development of combined hyperplastic processes in female reproductive system organs. fournal of obstetrics and women diseases. 2005; 54(2):31-35 (in Russ.)]

15. Правдин Е.В. Характеристика системы «перекисное окисление липидов - антиоксидантная защита» у больных с обострением хронических воспалительных заболеваний матки и придатков. Медищинская иммунология. 2017; 19(S):192-193 [Pravdin E.V. Characteristics of the system "lipid peroxidation-antioxidant protection" in patients with exacerbation of chronic inflammatory diseases of the uterus and appendages. Meditsinskaya immunologiya. 2017; 19(S):192-193 (in Russ.)]

16. Прилепская В.Н., Сехин С.В. Воспалительные заболевания органов малого таза: диагностика и ведение больных. Российский вестник акушерагинеколога. 2015; 15(4):101-106 [Prilepskaya V.N., Sekhin S.V. Small pelvic inflammatory diseases: Diagnosis and patient management tactics. Russian Bulletin of Obstetrician-Gynecologist. 2015; 15(4):101-106 (in Russ.)]

17. Соломатина Л.В. Клинико-диагностическая значимость определения С-реактивного белка в оценке хронического системного воспаления. Российский иммунологический журнал. 2015; 9-18(3):596-599 [Solomatina L.V. Clinical and diagnostic importance of C-reactive protein evaluation for assessment of chronic systemic inflammation. Russian Journal of Immunology. 2015; 9-18(3):596-599 (in Russ.)]

18. Снимщикова И.А., Шманева И.А., Акуленко Е.О., Снимщикова М.Д., Халилов М.А., Оболенская Т.И. Вторичная иммунная недостаточность на фоне воспалительных заболеваний органов малого таза. Российский иммунологический журнал. 2015; 9-18(1-1):181-182 [Snimshchikova I.A., Shmaneva I.A., Akulenko E.O., Snimshchikova M.D., Khalilov M.A., Obolenskaya T.I. Secondary immune insufficiency on the background of inflammatory diseases of the pelvic organs. Russian fournal of Immunology. 2015; 9-18(1-1):181-182 (in Russ.)]

19. Сухих Г.Т., Шуршалина А.В. Хронический эндометрит: руководство. Москва: ГЭОТАР-Медиа, 2013. 64 c. [Sukhikh G. T., Shurshalina A. V. Chronic endometritis: a guide. Moscow: GEOTAR-Media, 2013. 64 p. (in Russ.)]

20. Трунова Л.А., Трунов А.Н., Маринкин И.О., Кулешов В.M., Обухова О.О., Горбенко О.М., Шваюк А.П., Ваулин Д.Е. Дисбаланс цитокинов и активность иммуновоспалительного процесса у женщин с бесплодием. Аллергология и иммунология. 2014; 15(1):22-26 [Trunova L.A., Trunov A.N., Marinkin I.O., Kuleshov V.M., Obukhova O.O., Gorbenko O.M., Shvayuk A.P., Vaulin D.E. The imbalance of cytokines and the activity of inflammatory process in women with infertility. Allergologiya i immunologiya. 2014; 15(1):22-26 (in Russ.)] 
21. Трунова Л.А., Трунов А.Н., Обухова О.О., Шваюк А.П., Горбенко О.М., Анисимова Н.И. Иммунноэндокриные нарушения у девушек с хроническими воспалительными заболеваниями урогенитальной сферы как фактор будущих нарушений процессов гестации. Аллергология и иммунология. 2014; 15(3):212 [Trunova L.A., Trunov A.H., Obukhova O.O., Shvayuk A.P., Gorbenko O.M., Anisimova H.I. Immunoendocrine disorders in girls with chronic inflammatory diseases of the urogenital sphere as a factor of future disorders of gestation processes. Allergologiya i immunologiya. 2014; 15(3):212 (in Russ.)]

22. Яковлева Н.В. Хирургическое лечение трубного генеза: проблемы и решения. Вестник новых медицинских технологий. 2014; 21(1):121-127 [Yаkovleva N.V. Surgical treatment of the tubal infertility: issues and options. Fournal of New Medical Technologies. 2014; 21(1):121-127 (in Russ.)]
23. Ярилин Д.А. Роль фактора некроза опухолей в регуляции воспалительного ответа моноцитов и макрофагов. Иммунология. 2014; 15(4):195-201 [Yarilin D.A. Role of tumor necrosis factor in the regulation of the inflammatory response of monocytes and macrophages. Immunologiya. 2014; 15(4):195-201 (in Russ)]

24. Feldman N., Rotter-Maskowits A., Okun E. DAMPs as mediators of sterile inflammation in aging-related pathologies. Res Rev. 2015; 24(Pt A):29-39. DOI: 10.1016/j.arr.2015.01.003.

25. Shindler A.E. Pathophysiology, diagnosis and treatment of endometriosis. Minerva Ginecol. 2004; 56(5):419-435.

26. Spits H., Artis D., Colonna M., Diefenbach A., DiSanto J.P., Eberl G., Koyasu S., Loscley R.M. et al. Innate lymphoid cells - aproposal for a uniform nomenclature. Nat Rev Immunol. 2013; 13(2):145-149. DOI: 10.1038/nri3365.

Поступила в редакцию 15.07.2019

Подписана в печать 19.09.2019

Для цитирования: Конопля А.А., По Омашарифа Бинти Жамал, Иванова О.Ю., Елагина К.А. Иммунные и метаболические нарушения на системном и локальном уровне при бесплодии трубно-перитонеального генеза. Курский научно-практический вестник «Человек и его здоровье». 2019; (3):63-72. DOI: 10.21626/vestnik/2019-3/09

\title{
IMMUNE AND METABOLIC DISORDERS AT THE SYSTEMIC AND LOCAL LEVEL IN INFERTILITY OF TUBAL PERITONEAL GENESIS
}

\section{( Konoplya A.A., Poh Omasyarifa Binti Jamal, Ivanova O.Yu., Elagina K.A.}

\author{
Kursk State Medical University (KSMU)
}

3, K. Marx St., Kursk, Kursk region, 305041, Russian Federation

Objective. The establishment of immune and metabolic disorders at the systemic and local level in patients with infertility of tubal peritoneal genesis against the background of a chronic infectious-inflammatory process of the reproductive sphere in the stage of clinical remission before and after the basic pharmocotherapy.

Material and methods. A total of 96 patients with verified diagnosis of secondary infertility of tubal peritoneal genesis against the background of a chronic infectious and inflammatory process of bacterial viral etiology in the remission stage were under observation. The parameters of the immune status, the intensity of lipid peroxidation processes and the state of the antioxidant system were detected in peripheral blood and cervicovaginal lavage.

Results. Within 24 hours after diagnostic and treatment laparoscopy and basic pharmacotherapy had been conducted, the presence of immune inflammation, endothelial dysfunction, "oxidative stress", activation of lipid peroxidation processes was established at the systemic and local level, as evidenced by changes in $97.8 \%$ of laboratory immunometabolic parameters from the studied data. After conducted basic treatment, this percentage decreased to $90.9 \%$, while $9.1 \%$ returned to normal, $75.0 \%$ of contravene laboratory parameters were corrected, $15.9 \%$ remained unchanged at the same level before the treatment.

Conclusion. The obtained results indicate that the conducted basic pharmacotherapy in this category of patients has no adequate corrective effect on the impaired parameters of the immune and metabolic status that requires the additional pharmacological immuno-rehabilitation resources in this category of patients during pharmacological rehabilitation.

Keywords: infertility of tubal peritoneal genesis; immunometabolic disorders.

Konoplya Alexey A. - DM, Associate Professor, Professor of Department of Obstetrics and Gynecology of Post-Graduate Faculty, KSMU, Kursk, Russian Federation. ORCID iD: 0000-0001-5040-7499. E-mail: kanabis03101980@yandex.ru (correspondence author)

Poh Omasyarifa Binti Jamal - Assistant of the Department of Obstetrics and Gynecology of Post-Graduate Faculty, KSMU, Kursk, Russian Federation. ORCID iD: 0000-0002-4128-7576. E-mail: drmno131@yahoo.com

Ivanova Oksana Yu. - DM, Associate Professor, Professor of Department of Obstetrics and Gynecology, KSMU, Kursk, Russian Federation. ORCID iD: 0000-0003-2350-1740. E-mail: ivanovao1@mail.ru

Elagina Karina A. - Clinical Intern of Department of Obstetrics and Gynecology, KSMU, Kursk, Russian Federation. ORCID iD: 0000-0002-8186-0074. E-mail: karina.boeva.95@mail.ru 


\section{CONFLICT OF INTEREST}

The authors declare the absence of obvious and potential conflicts of interest related to the publication of this article.

\section{SOURCE OF FINANCING}

The authors state that there is no funding for the study.

\section{CONFORMITY WITH THE PRINCIPLES OF ETHICS}

The study was approved by the Regional Ethics Committee. The protocol of the meeting of the REC - N 4 of April, 8, 2019.

Received 15.07.2019

Accepted 19.09.2019

For citation: Konoplya A.A., Poh Omasyarifa Binti Jamal, Ivanova O.Yu., Elagina K.A. Immune and metabolic disorders at the systemic and local level in infertility of tubal peritoneal genesis. Kursk Scientific and Practical Bulletin "Man and His Health". 2019; (3):63-72. DOI: 10.21626/vestnik/2019-3/09. 